\title{
Amik ovasındaki yüzey su kaynaklarının kalitesi ve sulama ve içme amaçlı uygunluğunun değerlendirilmesi
}

Evaluation of the quality and their suitability for irrigation and drinking purposes of surface water resources in the Amik plain

\author{
Necat AĞCA ${ }^{1}$ (iD), Kemal DOĞAN ${ }^{1}$ (iD
}

${ }^{1}$ Hatay Mustafa Kemal Üniversitesi, Ziraat Fakültesi, Toprak ve Bitki Besleme Bölümü, Antakya-Hatay, Türkiye.

\section{MAKALE BILGISI / ARTICLE INFO}

\section{Makale tarihçesi / Article history:}

DOI: $10.37908 /$ mkutbd.991827

Geliş tarihi /Received:06.09.2021

Kabul tarihi/Accepted:02.11.2021

\section{Keywords:}

Water quality, surface water, Amik Plain, saturation index (PI).

\footnotetext{
Corresponding author: Necat AĞCA

$\bowtie$ : necagca@gmail.com
}

\section{ÖZET / A BSTRACT}

Atıf / Citation: Ağca N, Doğan K (2021) Amik ovasındaki yüzey su kaynaklarının kalitesinin ve bunların sulama ve içme amaçlı uygunluğunun değerlendirilmesi. MKU. Tar. Bil. Derg. 26(3) : 770-778. DOI: 10.37908/mkutbd.991827

\section{Giriş}

Yaşamın önemli bir parçası olan su, tüketilebilen doğal kaynaklardan biridir. Su kaynakları yer yüzeyinin yaklaşık 3/4'ünü kaplar. İnsanlar ve tüm canlılar için çok değerli bir kaynak olan su; İçme, yemek pişirme, çamaşır yıkama, sulama ve çiftlik kullanımı gibi birçok farklı amaç için kullanılmaktadır. İnsanların kullandığı su tatlı sudur ve bu dünyadaki toplam suyun \% 3'ünü oluşturur. Tatlı suyun sadece \% 10'u insan kullanımına uygundur ve yüzey veya yeraltı suyu şeklindedir. Kalan \% 90 buzullar ve kar şeklindedir (Rim-Rukeh ve ark., 2007). Bu nedenle suyun miktarı kadar kalitesi de önemlidir. 
Nehirler, verimli havzaları ve bol tatlı su kaynakları nedeniyle her zaman medeniyetin beşiği olmuştur. Nehir suyu içme, yıkama, hayvancılık, sanayi, tarım ve eğlence amaçlı kullanılmaktadır. Bununla birlikte, özellikle gelişmekte olan ülkelerde kontrol edilmeyen antropojenik faaliyetler, nehir suyunu giderek artan bir şekilde stresli ve sürdürülemez bir doğal kaynak haline getirmektedir. Endüstriyel atıklar, tarımsal akışlar, madencilik deşarjları, evsel atıklar ve belediye kanalizasyonlarının tümü nehir sularının kirlenmesine katkıda bulunur. Nehir suyu kaynaklarının daha iyi yönetimi ve sürdürülebilir gelişimi için sürekli izleme ve değerlendirme gereklidir (Manoj ve ark., 2013; Wang ve ark., 2020).

Yüzey suları, özellikle atık suların deşarjı nedeniyle kirlenmeye karşı oldukça hassastır (Samarghandi ve ark., 2007). Dünya genelindeki nehir havzalarının çoğunda, insan faaliyetleri besin maddelerinin peyzajdan yüzey sularına akışını değiştirerek su kalitesi üzerinde olumsuz etkilere yol açmaktadır (Smith 2003). Artan sanayileşme, kentleşme ve modern tarım uygulamaları, artan tatlı su talebi suyun kalitesini bozmaktadır (Yadav ve Kumar 2011). Yağış yüzey akışı, iç akış ve yeraltı suyu akışındaki mevsimsel değişim, nehir deşarjı ve dolayısıyla nehir suyundaki kimyasalların konsantrasyonları üzerinde güçlü bir etkiye sahiptir (Khadka ve Khanal 2008). Kabul edilemez kalitede su ile sulama toprağın kirlenmesine yol açar (Smith, 2003).

Yüzey su kalitesi konusunda Dünyanın farklı bölgelerinde çalışmalar yapılmıştır. Örneğin, Ruždjak ve Ruždjak (2015) yaptıkları bir araştırmada, çok değişkenli istatistiksel analiz tekniklerini kullanarak nehir suyu kalitesindeki değişimleri değerlendirmişlerdir. Araştırma sonuçlarına göre, belirlenen toplam 18 kalite parametresinden 6 parametrenin toplam variyansıdaki değişimin \% $75^{\prime}$ inden sorumlu olduklarını belirlemişlerdir.

Bilgin (2015) tarafından Çoruh (Artvin) havzası yüzey sularında yapılan bir çalışmada, suların ortalama sıcaklık $(T), p H$, elektriksel iletkenlik (EC), toplam çözünebilir katı (TDS), sodyum ( $\mathrm{Na})$, potasyum $(\mathrm{K})$, kalsiyum (Ca), magnezyum $(\mathrm{Mg})$, bikarbonat $\left(\mathrm{HCO}_{3}\right)$, toplam sertlik $(\mathrm{TH})$, klor $(\mathrm{Cl})$, sülfat $\left(\mathrm{SO}_{4}\right)$, amonyum $\left(\mathrm{NH}_{4}\right)$, nitrat $\left(\mathrm{NO}_{3}\right)$, fosfat $\left(\mathrm{PO}_{4}\right)$ ve çözünmüş oksijen (DO) değerleri sırasıyla; $22.4{ }^{\circ} \mathrm{C}, 7.87,32.53 \mathrm{mS} \mathrm{cm}^{-1}, 223.56 \mathrm{mg} \mathrm{L}^{-1}, 9.87 \mathrm{mg} \mathrm{L}^{-1}$, $1,62 \mathrm{mg} \mathrm{L}^{-1}, 36.39 \mathrm{mg} \mathrm{L}^{-1}, 11.08 \mathrm{mg} \mathrm{L}^{-1}, 85.21 \mathrm{mg} \mathrm{L}^{-1}$, $142.55 \mathrm{mg} \mathrm{L}^{-1}, 4.58 \mathrm{mg} \mathrm{L}^{-1}, 127.25,0.20 \mathrm{mg} \mathrm{L}^{-1}, 1.57 \mathrm{mg} \mathrm{L}^{-}$ ${ }^{1} \mathrm{~L}, 0.65 \mathrm{mg} \mathrm{L}^{-1}, 5.29 \mathrm{mg} \mathrm{L}^{-1}$ olarak belirlenmiştir. Yine çalışmada yapılan faktör analiz sonuçlarına göre, toplam varyansın \% 81.3'ünü beş faktörün açıkladığı belirlenmiştir.

Tayland'da Muangthong ve Shrestha (2021) tarafından
Nampong Songkhve Ram nehirlerinde yapılan çalışmalarda, su kalitesi; klastır analizi ve prinsipal komponent analizi gibi çok değişkenli istatistiksel teknikler kullanılarak araştırılmıştır. Analiz sonuçlarına göre, toplam varyansın anılan nehirlerde sırasıyla \% 69.80 ve $\% 69.32$ 'si incelenen toplam 16 parametreden beşinden kaynaklanmıştır.

Ustaoğlu ve ark. (2019) tarafından yapılan bir çalışmada Turnasuyu Havzasında tarımsal faaliyetlerin ve evsel kirliliğin su kalitesine etkisi değerlendirilmiştir. Değerlendirmede farklı kıstaslar kullanılmıştır. Çalışma sonunda Turnasuyu Çayı'nın çok iyi bir su kalitesi özelliğine sahip olduğu ve belirlenen eser elementlerin halk sağlığı açısından tehlikeli sınırlarda olmadığı belirlenmiştir.

Hindistan'ının Jharkhan bölgesinde yapılan bir çalışmada madencilik uygulamalarının yüzey su kalitesine etkileri araştırılmıştır. Araştırma sonuçlarına göre, madencilik uygulamalarının yüzey suyu kalitesini önemli ölçüde bozduğu belirlenmiştir (Prathap ve Chakraborty, 2020).

Ustaoğlu ve ark. (2021) tarafından, Karadeniz bölgesinde yer alan Terme Nehri'nin su kalitesi üzerine yaptıkları bir çalışmada, katyon konsantrasyonlarının çoktan aza doğru $\mathrm{Ca}^{2+}>\mathrm{Mg}^{2+}>\mathrm{Na}^{+}>\mathrm{K}^{+}>\mathrm{NH}_{4}{ }^{+}$şeklinde sıralandığı ve nehir kalitesindeki önemli değişikliklerin; havzanın kayaç tipleri, toprak erozyonu, kentsel atıkların deşarjı ve tarımda kullanılan inorganik gübrelerden kaynaklandığı belirlenmiştir.

Pakistan'ın Skardu bölgesinde yapılan bir çalışmada, yüzey sularının içme suyu olarak kullanılabilmesi araştırılmıştır. Çalışma sonucunda bölgedeki su kaynaklarının; toplam çözünebilir katı (TDS), kelley oranı (KR) ve geçirgenlik indeksi (PI) parametreleri yönünden içme amaçlı kullanılabilir olduğu belirlenmiştir (Ahsan ve ark., 2021).

Mısır'ın Damietta bölgesinde yapılan bir çalışmada, Nil nehrinin yüzey su kalitesindeki yersel ve zamansal değişiklikler incelenmiştir. Araştırma sonuçları, genellikle su kalitesindeki yersel değişikliğin, zamansal değişiklikten daha az olduğunu göstermiştir. Anova test sonuçlarına göre çoğu su parametrelerindeki yersel değişim istatistiksel açıdan önemli bulunmuştur. Yine kalite parametrelerinin tamamına yakın kısmının değerleri Uluslararası sağlık örgütünün (WHO) içme suları için belirlediği standart değerlerden daha fazla olduğu belirlenmiştir (Taher ve ark., 2021).

Brezilya'da Lorrane de Oliveira ve ark. (2021) tarafından yapılan bir çalışmada, yüzey su kalitesindeki 10 yıllık değişim incelenmiştir. Çalışma sonunda su kalitesinde zamana bağlı değişimler belirlenmiş ve su kalitesindeki değişikliklerden bu değişimlerden tarımsal faaliyetleri ve bölgenin jeokimyasal özelliklerinin sorumlu olduğu 
saptanmıştır.

Bu çalışmada, Türkiye'nin en önemli tarımsal üretim alanlarından biri olan Amik Ovası'nın yüzey sularının özelliklerinin belirlenmesi ve bunların sulama suyu ve içme suyu kalitesi açısından değerlendirilmesi amaçlanmıştır. Amik ovası yeraltı sularında yapılan çalışmalarda (Ağca, 2014; Ağca ve ark. 2014), yeraltı sularının bir kısmında tuzluluk sorunları belirlenmiştir. Benzer sorunların yüzey sularında da olma olasılığının yüksek olduğu tahmin edilmektedir. Bu çalışmada, benzer sorunların yüzey sularında da olup olmadığı araştırılmıştır. Ayrıca yüzey sularına ait verilere t testi uygulanarak, su kalitesindeki zamana bağlı değişimler belirlenmiştir.

\section{MATERYAL VE YÖNTEM}

Hatay il sınırları içinde yer alan Amik Ovası $35^{\circ} 48^{\prime}$ ve $36^{\circ} 24^{\prime}$ doğu boylamları, $35^{\circ} 48^{\prime}$ ve $36^{\circ} 37^{\prime}$ kuzey enlemleri arasında kalmakta olup, yaklaşık 72500 hektarlık bir alan kaplamaktadır (Şekil 1). Çalışma alanı doğuda Reyhanlı ilçesi ve Suriye, batıda Nur dağları, kuzeyde Kırıkhan ilçesi, güneyde ise Antakya ilçesi ve Suriye ile sınırlandırılmıştır (Kılıç ve ark., 2008). Amik ovasının güneyinde Asi nehri, doğusunda Afrin çayı, kuzeyinde ise Karasu çayları bulunmaktadır. Araştırma alanı kışları yağışlı, yazları ise kurak ve sıcak Akdeniz ikliminin etkisi altındadır. Hatay' da yıllık ortalama sıcaklık $18^{\circ} \mathrm{C}$, yıllık ortalama toplam yağış ise $1124 \mathrm{~mm}$ 'dir (Gün ve Erdem 2003).

Bu çalışmada, Amik ovasında yer alan su kaynaklarından Haziran 2017' de toplam 56 noktadan su örneği alınmıştır (Şekil 1). Örneklerin 13 tanesi $(1,4,5,6,7,8,9,10,12$, $13,14,15,16$ nolu örnekler) Comba kanalından, 17 tanesi $(2,3,19,20,21,22,23,24,25,26,27,28,29,30$, 31,33 ve 34 nolu örnekler) Karasu çayından, 10 tanesi $(35,36,37,38,39,40,41,42,43$ ve 44 nolu örnekler) Muratpaşa kanalından, 9 tanesi $(47,48,49,50,51,52$, 53, 54 ve 55 nolu örnekler) Afrin çayından, 3 tanesi (56, 57, 58 nolu örnekler) Küçük Asi'den, 4 tanesi ise (59, 60, 61, 62 nolu örnekler) Asi nehrinden alınmıştır. Eylül 2017'de ise, Haziran ve Eylül arasındaki değişiklikleri belirlemek amacı ile 56 noktanın 43'ünden yeniden su örneği daha alınmıştır.

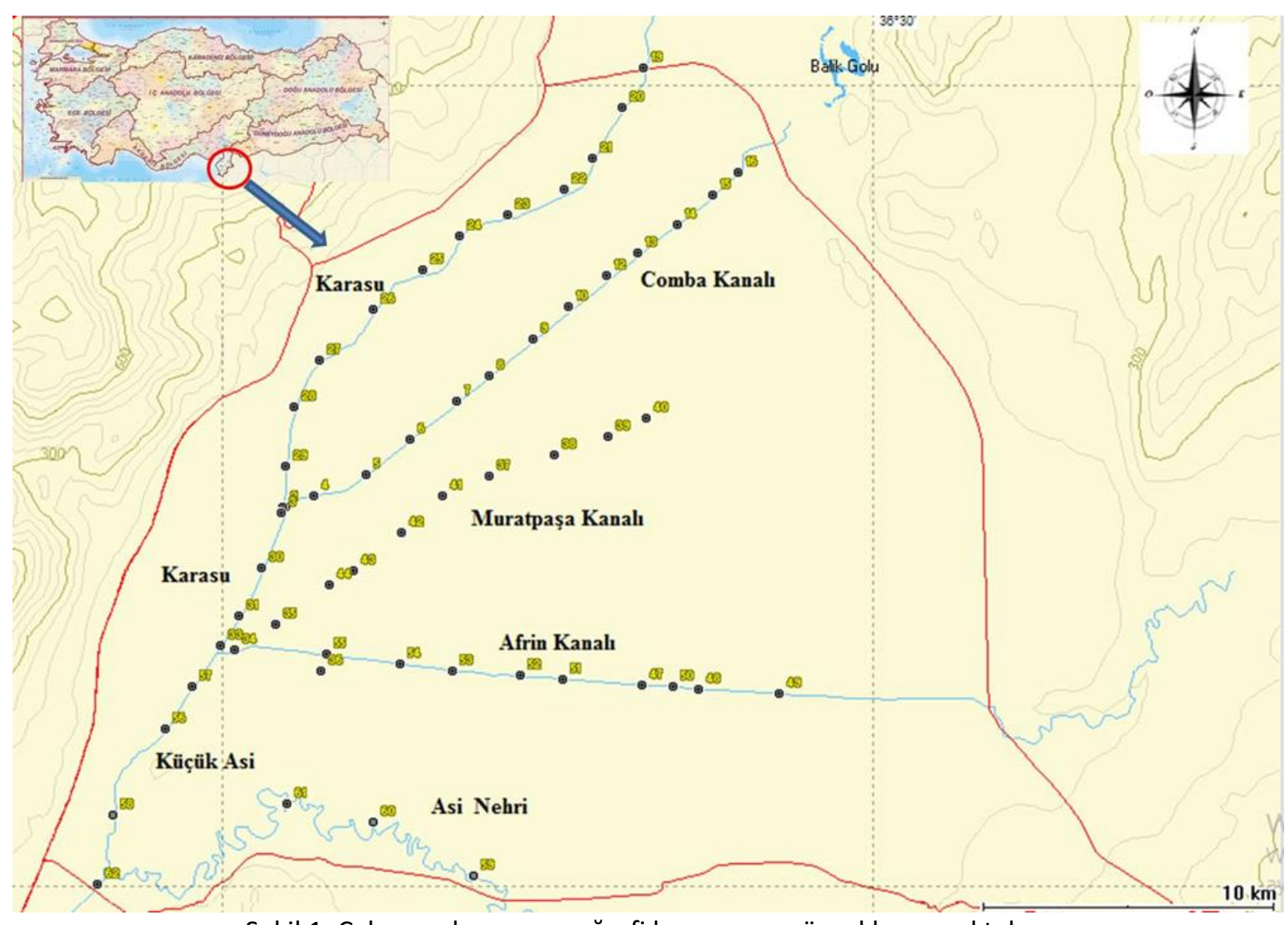

Şekil 1. Çalışma alanınının coğrafi konumu ve örnekleme noktaları.

Figure 1. Geographical location of the study area and sampling points. 
Su örneklerinin alındığı tüm noktaların UTM sistemine göre coğrafi koordinatları, konum belirleme cihazı (GPS) ile belirlenmiştir. Örnekler $500 \mathrm{ml}$ hacimli polietilen su kapları ile alınmış, su kapları örnek konulmadan önce musluk suyu ve saf su ile yıkanıp temizlenmiştir. Ayrıca, örnek alım sırasında ise su kapları alınan su ile üç kez çalkalanmıştır. Katyon analizleri için alınan örneklere, mikrobiyel bozulmayı önlemek için nitrik asit $\left(\mathrm{HNO}_{3}\right)$ eklenmiştir. Örnekler anı gün güvenli bir şekilde laboratuvara getirilerek analiz edilene kadar buzdolabında $+4{ }^{\circ} \mathrm{C}^{\prime}$ de saklanmıştır.

Yüzey suyu örneklerinde; elektriksel iletkenlik (EC), toplam çözünebilir katı (TDS), pH, eriyebilir katyon ( $\mathrm{Na}$, $\mathrm{K}, \mathrm{Ca}, \mathrm{Mg}$ ) ve anyon $\left(\mathrm{CO}_{3}, \mathrm{HCO}_{3}, \mathrm{Cl}\right.$ ve $\left.\mathrm{SO}_{4}\right)$ analizleri yapılmıştır. Bu özelliklerden; elektriksel iletkenlik (EC), toplam çözünebilir katı (TDS), $\mathrm{pH}, \mathrm{Cl}$ gibi parametreler hemen örneği alır almaz veya akarsularda, multiprob (YSI Professional Plus) cihazı ile doğrudan doğal koşullarda ölçülmüştür. Sodyum ( $\mathrm{Na}$ ) ve potasyum $(\mathrm{K})$ fleym fotometrede, kalsiyum (Ca) ve magnezyum $(\mathrm{Mg})$ tayinleri ise atomik adsorpsiyon spektrofotometresinde yapılmıştır. Karbonat ve bikarbonat iyonları sülfürik asit ile titrasyon yöntemi ile belirlenmiş, sülfat ise toplam katyon miktarından, üç anyonun $\left(\mathrm{CO}_{3}, \mathrm{HCO}_{3}\right.$ ve $\left.\mathrm{Cl}\right)$ toplamı çıkartılarak hesaplanmıştır (Richards, 1954).

Belirlenen sodyum ( $\mathrm{Na}$ ) kalsiyum (Ca) ve magnezyum $(\mathrm{Mg})$ değerlerinden sodyum adsorpsiyon oranı (SAR), karbonat $\left(\mathrm{CO}_{3}\right)$, bikarbonat $\left(\mathrm{HCO}_{3}\right)$, kalsiyum ve magnezyum değerlerinden kalıcı sodyum karbonat (RSC), kalsiyum ve magnezyum değerlerinden ise toplam sertlik (TS) ve magnezyum oranı (MR), bikarbonat $\left(\mathrm{HCO}_{3}\right)$ ve eriyebilir katyonlardan ise geçirgenlik indexi (PI) değerleri hesaplanmıştır. Hesaplanan, SAR, RSC, TS, $M R$, PI değerleri yorumlanarak suların kalitesi ve sınıflandırıması yapılmıştır. Bu değerlerin hesaplama formülleri aşağıda verilmiştir:

$\mathrm{SAR}=\mathrm{Na} / \mathrm{V}[(\mathrm{Ca}+\mathrm{Mg}) / 2] \quad($ Eşitlik 1) $\quad($ Richards, 1954) $\mathrm{RSC}=\left(\mathrm{CO}_{3}+\mathrm{HCO}_{3}\right)-\left(\mathrm{Ca}^{+2}+\mathrm{Mg}^{+2}\right) \quad$ (Eşitlik 2) (Eaton,1950) $\mathrm{TS}=\left(\mathrm{CaCO}_{3} \quad\right.$ olarak, $\left.\mathrm{mg} / \mathrm{L}\right)=\left(\mathrm{Ca}^{+2}+\mathrm{Mg}^{+2}\right) \quad \mathrm{me} / \times 50$ (Eşitlik 3) (Arumugam ve Elangovan, 2009)

$\mathrm{MR}=\mathrm{Mg}^{+2} \times 100 /\left(\mathrm{Ca}^{+2}+\mathrm{Mg}^{+2}\right)$ burada birimler $\mathrm{mg} / \mathrm{L}^{\prime}$ dir (Eşitlik 4) (Prasanth ve ark. 2012)

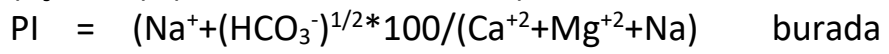
birimler me $\mathrm{L}^{1}$ 'dir (Eşitlik 5) (Doneen, 1964 tarafından geliştirilmiştir) (Zeeshan ve Azeez, 2016).

Su örneklerinin fizikokimyasal özelliklerdeki farklılıkları ve dağılımları açıklayabilmek için tanımlayıcı istatistiksel analiz (ortalama, en az, en fazla, varyasyon katsayısı); su örneklerinin özellikleri arasındaki örnekleme dönemleri arasındaki farklııkları açıklayabilmek için ise $t$ testi yapılmıştır. Tüm istatistik analizlerde SSPS 18.0 istatistik paket programı kullanıımıştır.

\section{BULGULAR ve TARTIŞMA}

\section{Yüzey sularının fizikokimyasal özellikleri}

Çalışma alanında Haziran dönemindeki yüzey sularının özelliklerine ait tanımlayıcı istatistik analiz sonuçları Çizelge 1 'de verilmiştir. Haziran döneminde en yüksek konsantrasyona sahip eriyebilir katyonun $\mathrm{Mg}$ (ortalama: $13.28 \mathrm{me} \mathrm{L}^{-1}$ ), en düşük katyonun ise $\mathrm{K}$ (ortalama: 0.10 me $\mathrm{L}^{-1}$ ) olduğu belirlenmiştir. Aynı dönemde eriyebilir anyonlar arasında en yüksek değere $\mathrm{SO} 4$ (ortalama: $10.40 \mathrm{me} \mathrm{L}^{-1}$ ) sahipken, en düşük değere sahip anyon ise $\mathrm{CO}_{3}+\mathrm{HCO}_{3}$ toplamı (ortalama: $4.90 \mathrm{me} \mathrm{L}^{-1}$ ) olarak belirlenmiştir. En yüksek magnezyum konsantrasyonu (94.50 $\mathrm{me} \mathrm{L}^{-1}$ ) 37 nolu örnekleme noktasında, en yüksek $\mathrm{K}$ konsantrasyonu ( $\left.0.38 \mathrm{me} \mathrm{L}^{-1}\right)$ ise 49 nolu örnekleme noktasında belirlenmiştir. Ortalama değerlere göre katyonların bolluk sırası $\mathrm{Mg}^{+2}>\mathrm{Na}^{+}>\mathrm{Ca}^{+} 2>\mathrm{K}^{+}$şeklinde belirlenmiştir. En yüksek $\mathrm{SO}_{4}$ değeri $\left(85.85 \mathrm{me} \mathrm{L}^{-1}\right) 37$ nolu örnekleme noktasında, en düşük $\mathrm{CO}_{3}+\mathrm{HCO}_{3}$ değeri (3.00 $\mathrm{me} \mathrm{L} \mathrm{L}^{-1}$ ) ise 15 nolu örnekleme noktasında belirlenmiştir. Ortalama değerlere göre anyonların bolluk sırası $\mathrm{SO} 4>\mathrm{Cl}>\mathrm{CO}_{3}+\mathrm{HCO}_{3}$ şeklidedir.

Haziran döneminde, en düşük varyasyon katsayısı (4.2) $\mathrm{pH}$, en yüksek varyasyon katsayısı (170.0) ise klor (Cl) değerlerinde saptanmıştır (Çizelge 1). Genellikle varyasyon katsayısı \% 10'dan düşük ise düşük değişkenlik, \% 10-100 arasında ise orta düzeyde değişkenlik ve \% 100'den büyük ise yüksek düzeyde değişkenlik olduğu kabul edilmektedir (Zhou ve ark. 2011). Bu sınıflamaya göre; $\mathrm{pH}$ düşük; $\mathrm{K}, \mathrm{Ca}, \mathrm{SAR}, \mathrm{CO}_{3}+$ $\mathrm{HCO}_{3}, \mathrm{PI}, \mathrm{MR}$ değerleri orta; diğer parametreler ise yüksek değişkenlik göstermişlerdir. Düşük değişkenlik homojen dağılıma, yüksek değişkenlik ise homojen olmayan dağılımı belirtmektedir. Diğer yandan $\mathrm{pH}$ ve MR parametrelerinin yatıklık değeri 1'den düşük olduğu için normal dağılım göstermiş (Goovaerts, 1999), diğer parametreler ise normal dağılım göstermemiştir.

Çalışma alanında Eylül dönemindeki yüzey sularının özelliklerine ait tanımlayıcı istatistik analiz sonuçları Çizelge 2'de verilmiştir.

Eylül döneminde, en düşük varyasyon katsayısı (4.8) pH, en yüksek varyasyon katsayısı (179.0) ise $\mathrm{SO}_{4}$ değerlerinde saptanmıştır. $\mathrm{Bu}$ dönemde $\mathrm{pH}^{\prime}$ ıın düşük, $\mathrm{Ca}, \mathrm{SAR}, \mathrm{CO}_{3}{ }^{+} \mathrm{HCO}_{3}$ ve MR orta, diğer parametrelerin ise yüksek değişkenliğe sahip olduğu belirlenmiştir. Ortalama değerlere göre, dominant katyon bu dönemde de $\mathrm{Mg}$ (en yüksek değer: $91.70 \mathrm{me} \mathrm{L}^{-1}$ ) iken en düşük konsantrasyona sahip katyon ise $K$ (en düşük değer: 0.02 me $\mathrm{L}^{-1}$ ) olarak belirlenmiştir (Çizelge 2). En yüksek $\mathrm{Mg}$ değeri 37 nolu örnekleme noktasında, en düşük K değeri ise 19 nolu örnekleme noktasında belirlenmiştir. 
Çizelge 1. Çalışma alanındaki yüzey sularının Haziran dönemindeki fiziko-kimyasal parametrelerin tanımlayıcı istatistik analiz sonuçları $(n=56)$

Table 1. Descriptive statistical analysis results of physico-chemical parameters of surface waters in the study area in June $(n=56)$

\begin{tabular}{|c|c|c|c|c|c|c|c|}
\hline Parametre & Birim & En düşük & En yüksek & Ortalama & $\begin{array}{c}\text { Standart } \\
\text { Sapma }\end{array}$ & $\begin{array}{l}\text { Varyasyon } \\
\text { Katsayısı \% }\end{array}$ & Yatıklık \\
\hline $\mathrm{pH}$ & --- & 7.58 & 9.42 & 8.57 & 0.36 & 4.2 & -0.17 \\
\hline $\mathrm{EC}$ & $\mu S \mathrm{~cm}^{-1}$ & 906.0 & 20144.0 & 4060.2 & 4545.2 & 111.9 & 2.45 \\
\hline TDS & $\mathrm{mg} \mathrm{L}^{-1}$ & 591.5 & 13078.0 & 2410.1 & 2686.3 & 111.4 & 2.90 \\
\hline $\mathrm{Na}$ & $\mathrm{me} \mathrm{L}^{-1}$ & 0.38 & 30.85 & 4.73 & 6.25 & 132.1 & 2.86 \\
\hline $\mathrm{K}$ & $\mathrm{me} \mathrm{L}^{-1}$ & 0.01 & 0.38 & 0.10 & 0.08 & 80.0 & 2.03 \\
\hline $\mathrm{Ca}$ & $\mathrm{me} \mathrm{L}^{-1}$ & 1.31 & 17.19 & 4.24 & 3.08 & 72.6 & 2.64 \\
\hline $\mathrm{Mg}$ & $\mathrm{me} \mathrm{L}^{-1}$ & 2.67 & 94.50 & 13.28 & 19.65 & 148.0 & 2.95 \\
\hline SAR & --- & 0.22 & 5.19 & 1.45 & 1.08 & 74.5 & 1.74 \\
\hline $\mathrm{HCO}_{3}+\mathrm{CO}_{3}$ & $\mathrm{me} \mathrm{L}^{-1}$ & 3.00 & 8.60 & 4.90 & 1.07 & 21.8 & 1.21 \\
\hline $\mathrm{Cl}$ & $\mathrm{me} \mathrm{L}^{-1}$ & 0.80 & 64.10 & 7.05 & 11.99 & 170.0 & 3.63 \\
\hline $\mathrm{SO}_{4}$ & $\mathrm{me} \mathrm{L}^{-1}$ & 0.18 & 85.85 & 10.40 & 17.36 & 166.9 & 2.68 \\
\hline RSC & $\mathrm{me} \mathrm{L}^{-1}$ & $-103,43$ &,- 0.57 & $-12,62$ & 22,33 & -1.77 & -2.96 \\
\hline TS & $\mathrm{mg} \mathrm{L}^{-1}$ & 269.1 & 5441.3 & 876.3 & 1131.3 & 129.1 & 2.92 \\
\hline MR & $\%$ & 35.0 & 85.5 & 55.9 & 11.8 & 21.1 & 0.60 \\
\hline $\mathrm{PI}$ & $\mathrm{me} \mathrm{L}^{-1}$ & 18.5 & 65.6 & 35.5 & 9.1 & 25.6 & 0.84 \\
\hline
\end{tabular}

Çizelge 2. Çalışma alanında Eylül döneminde yüzey sularının fiziko-kimyasal parametrelerin tanımlayıcı istatistik analiz sonuçları $(n=43)$

Table 2. Descriptive statistical analysis results of physico-chemical parameters of surface waters in the study area in September $(n=43)$

\begin{tabular}{|c|c|c|c|c|c|c|c|}
\hline Parametre & Birim & En düşük & En yüksek & Ortalama & $\begin{array}{c}\text { Standart } \\
\text { Sapma }\end{array}$ & $\begin{array}{c}\text { Varyasyon } \\
\text { Katsayısı }\end{array}$ & Yatıklık \\
\hline $\mathrm{pH}$ & --- & 7.62 & 9.75 & 8.39 & 0.40 & 4.8 & 0.85 \\
\hline EC & $\mu \mathrm{S} \mathrm{cm^{-1 }}$ & 903 & 15970 & 2835.9 & 3445.1 & 121.5 & 2.80 \\
\hline TDS & $\mathrm{mg} \mathrm{L}^{-1}$ & 585 & 10380 & 1842.4 & 2238.8 & 121.5 & 2.80 \\
\hline $\mathrm{Na}$ & $\mathrm{me} \mathrm{L}^{-1}$ & 0.76 & 55.48 & 7.94 & 11.42 & 143.8 & 2.93 \\
\hline $\mathrm{K}$ & $\mathrm{me} \mathrm{L}^{-1}$ & 0.02 & 0.96 & 0.14 & 0.16 & 114.3 & 3.83 \\
\hline $\mathrm{Ca}$ & $\mathrm{me} \mathrm{L}^{-1}$ & 1.39 & 17.25 & 3.85 & 3.79 & 98.4 & 2.62 \\
\hline $\mathrm{Mg}$ & $\mathrm{me} \mathrm{L}^{-1}$ & 2.52 & 91.70 & 15.08 & 21.42 & 141.9 & 2.70 \\
\hline SAR & --- & 0.38 & 7.52 & 2.27 & 1.73 & 76.2 & 1.80 \\
\hline $\mathrm{HCO}_{3}+\mathrm{CO}_{3}$ & $\mathrm{me} \mathrm{L}^{-1}$ & 2.80 & 8.60 & 5.07 & 1.41 & 27.8 & 0.99 \\
\hline $\mathrm{Cl}$ & $\mathrm{me} \mathrm{L}^{-1}$ & 1.39 & 78.25 & 11.56 & 17.31 & 149.7 & 3.06 \\
\hline $\mathrm{SO}_{4}$ & $\mathrm{me} \mathrm{L}^{-1}$ & 0.16 & 80.21 & 10.37 & 18.56 & 179.0 & 2.57 \\
\hline RSC & $\mathrm{me} \mathrm{L}^{-1}$ & -102.5 & -0.99 & -13.9 & 24.16 & -1.74 & -2.78 \\
\hline TS & $\mathrm{mg} \mathrm{L}^{-1}$ & 240.7 & 5447.5 & 946.3 & 1257.1 & 132.8 & 2.71 \\
\hline $\mathrm{MR}$ & $\%$ & 27.1 & 78.5 & 63.9 & 11.5 & 18.0 & -1.36 \\
\hline $\mathrm{PI}$ & $\mathrm{me} \mathrm{L}^{-1}$ & 21.6 & 67.9 & 41.13 & 9.64 & 23.4 & 0.09 \\
\hline
\end{tabular}

$t$ test sonuçlarına göre (Çizelge 3), Haziran dönemindeki ortalama $\mathrm{pH}$ değeri, Eylül dönemi $\mathrm{pH}$ değerlerinden istatistiksel olarak anlamlı bir şekilde yüksek bulunmuştur $(p<0.05)$. Diğer yandan, Eylül dönemindeki ortalama SAR değeri, Haziran dönemindeki SAR değerinden istatistiksel olarak \%1 düzeyinde önemli bulunmuştur. Diğer parametrelerde de mevsimler arasında farklılıklar bulunmuştur. Ancak, bu farklılıklar istatistiksel açıdan önemli bulunmamıştır (Çizelge 3).

\section{Yüzey sularının sulama amaçlı uygunluğu}

Yüzey sularının sulama amaçlı uygunluğunun değerlendirilmesinde $\mathrm{pH}, \mathrm{EC}, \mathrm{SAR}, \mathrm{RSC}, \mathrm{MR}$ ve $\mathrm{PI}$ değerleri dikkate alınmıştır. Değerlendirmedeki yüzey suları, her iki dönem olarak birlikte dikkate alınmıştır.

Her iki dönemde $\mathrm{pH}$ değerleri 7.58 ile 9.75 arasında değişmiştir (Çizelge 1 ve 2). Sulama sularında $\mathrm{pH}^{\prime}$ sı 8.5'den yüksek olan örneklerin alındığı noktalarda sular $\mathrm{pH}$ açısından sulamaya uygun değildir (Richards, 1954). 
Bu değerlendirmeye göre, toplam 99 örneğin yaklaşık \% $44^{\prime} \mathrm{ü} \mathrm{pH}$ açısından sulamaya uygun değildir. $\mathrm{pH}$ 'sı 8.5'in üzerinde olan sularla sulanan topraklarda alkalileşme sorunu görülmektedir (Richards, 1954). Ancak çalışma alanında yapılan araştırmalarda topraklarda alkalilik sorununa rastlanmamıştır (Keskin ve ark., 1999; Ağca ve ark., 2000; Kılıç ve ark., 2008).

Çizelge 3. Çalışma alanındaki yüzey sularında örnekleme zamanları arısındaki t test sonuçları (güven sınırı: \% 95) ( $n=43$ )

Table 3. $t$ test results between sampling times in surface waters in the study area (confidence limit: $95 \%)(n=43)$

\begin{tabular}{|c|c|c|c|c|c|c|c|c|c|}
\hline $\begin{array}{l}\text { Para- } \\
\text { metre }\end{array}$ & Zaman & Ortalama & $t$ & $\begin{array}{c}\text { Önem } \\
\text { Derecesi }\end{array}$ & Parametre & Zaman & Ortalama & $t$ & $\begin{array}{c}\text { Önem } \\
\text { Derecesi }\end{array}$ \\
\hline \multirow[t]{2}{*}{$\mathrm{pH}$} & Haziran & 8.56 & 2.06 & $0.04^{*}$ & SAR & Haziran & 1.42 & 2.76 & $0.00 * *$ \\
\hline & Eylül & 8.39 & & & & Eylül & 2.27 & & \\
\hline \multirow[t]{2}{*}{ EC } & Haziran & 4332 & 1.60 & 0.11 & $\mathrm{HCO}_{3}+\mathrm{CO}_{3}$ & Haziran & 4.88 & 0.74 & 0.46 \\
\hline & Eylül & 2835 & & & & Eylül & 5.07 & & \\
\hline \multirow[t]{2}{*}{ TDS } & Haziran & 2521 & 1.19 & 0.24 & $\mathrm{Cl}$ & Haziran & 7.74 & 1.14 & 0.26 \\
\hline & Eylül & 1842 & & & & Eylül & 11.56 & & \\
\hline \multirow[t]{2}{*}{$\mathrm{Na}$} & Haziran & 4.96 & 1.46 & 0.15 & SO4 & Haziran & 11.21 & 0.21 & 0.84 \\
\hline & Eylül & 7.93 & & & & Eylül & 10.37 & & \\
\hline \multirow[t]{2}{*}{$\mathrm{K}$} & Haziran & 0.10 & 1.64 & 0.11 & MR & Haziran & 55.6 & 3.26 & $0.00 * *$ \\
\hline & Eylül & 0.14 & & & & Eylül & 63.9 & & \\
\hline \multirow[t]{2}{*}{$\mathrm{Ca}$} & Haziran & 4.40 & 7.10 & 0.48 & TS & Haziran & 938.3 & 0.30 & 0.98 \\
\hline & Eylül & 3.85 & & & & Eylül & 946.3 & & \\
\hline \multirow[t]{2}{*}{$\mathrm{Mg}$} & Haziran & 14.36 & 0.15 & 0.88 & $\mathrm{PI}$ & Haziran & 35.1 & 3.05 & $0.00 * *$ \\
\hline & Eylül & 15.07 & & & & Eylül & 41.1 & & \\
\hline
\end{tabular}

\section{EC ve SAR}

Elektriksel iletkenlik sularda tuzluluğun bir ölçüsüdür. Elektriksel iletkenlik arttıkça, sulardaki tuz miktarı da artmaktadır. Bu nedenle EC tuzluluğun bir ölçüsü olarak kullanılmaktadır. Suların EC değerleri arttıkça sulamaya uygunlukları azalmaktadır. Yüzey sularında EC değerleri çok geniş bir sınır içinde değişmektedir (Çizelge 1 ve 2). Yine, suların SAR değerleri ise sodyum varlığının bir ölçüsü olup, SAR değeri arttıkça sulamaya uygunluk azalmaktadır.

EC ve SAR değerlerinin sulamaya uygunluğu Amerika tuzluluk laboratuvarı diyagramına göre değerlendirilmektedir (Ayers ve Westcot, 1994). Bu diyagramda tuzluluk $C$, alkalilik ise $S$ sembolü ile gösterilmiş ve bunların kombinasyonu olan 16 farklı su kalite sınıfı oluşturulmuştur. Amerika tuzluluk laboratuvarı diyagramına göre; yüzey suyu örneklerinin her iki dönemde \% 51.4'ü C3S1 sınıfındadır. Bu sınıfa giren sular yüksek tuzlu ve düşük sodyumlu sulardır. Tuzluluk yönünden sulamaya uygun değilken, sodyumluluk yönünden uygundurlar. Suların \% 29.4'ü C4S1 sınıfına girmişlerdir. Bu sınıftaki sular çok tuzlu ve az sodyumlu sular olup, tuzluluk yönünden sulamaya uygun değil, sodyumluluk yönünden ise uygundurlar. Suların her iki dönemde, \% 15.6'sı C4S2 sınıfında sınıflanmıştır. Bu sınıf sular da tuzluluk yönünden sulamaya uygun olmayıp, soduyumluluk yönünden ise ancak bazı sodyuma dayanıklı bitkiler için uygundur.
Suların \% 3.6'sı ise C4S3 sınıfında olup bu sular hem tuzluluk hem de sodyumluluk yönünden hemen hemen tüm bitkiler için sulamaya uygun değildir.

\section{RSC ve PI}

Aşırı miktarda $\mathrm{HCO}_{3}$ ve $\mathrm{CO}_{3}$ içeren sular, toprak çözeltisinde bulunan $\mathrm{Ca}^{+2}$ ve $\mathrm{Mg}^{+2}$ katyonları ile reaksiyona girerek kalsit ve manyezit olarak çökeltmektedir. Bu, adsorbe edilen sodyumun kil yüzeylerine hâkim olmasına, toprağın sodyum tehlikesini artıran değişebilir sodyum yüzdesini (ESP) artırmaktadır. $\mathrm{Bu}$ durum da toprak geçirgenliğini ve toprak havalanmasının azalmasına, $\mathrm{pH}^{\prime}$ nın yükselmesine ve köklerin toprağa girmesinin engellemesine neden olmaktadır (Ayers ve Westcot, 1994).

Suların sulamaya uygunluğunun değerlendiril-mesinde kullanılan diğer bir ölçüt de sodyum karbonat fazlalığı (RSC)'dir. Pozitif RSC değerleri topraklarda bir yandan pH'nın yükselmesine neden olmakta, diğer yandan topraklarda sodyumun fazla tutulmasını sonuçlanmaktadır (Wang, 2013). Çalışma alanından alınan tüm yüzey suyu örneklerinde her iki dönemde de RSC değerlerinin tamamı negatif çıkmıştır. Bu nedenle, RSC değerlerine göre, tüm örnekler sulama için uygundur.

Yüzey suların sulamaya uygunluğunun değerlendirilmesinde kullanılan diğer bir kıstas da geçirgenlik indeksidir. Geçirgenlik indeksi (PI), suların 
kalitesinin toprağın fiziksel özellikleri üzerindeki olası etkilerini değerlendirmek amacıyla kullanılmaktadır. Sulama suyu kalitesinin toprağın fiziksel özellikleri üzerindeki uzun süreli etkileri, esas olarak sulama suyunun toplam tuz $\left(\mathrm{Na}^{+}, \mathrm{HCO}_{3}^{-}\right.$ve $\left.\mathrm{CO}_{3}^{-}\right)$ konsantrasyonlarına ve ilk toprak özelliklerine bağlıdır (Kırda, 1997). PI yönünden sular III sınıfa ayrılmıştır. Su, sınıf I (PI $\geq 75$ olduğunda), sınıf $\|$ (PI = \% 25-75 olduğunda) ve sınıf III (PI $\leq \% 25$ olduğunda) olarak sınıflandırılır. I. ve I.I Sınıf sular sulamaya uygun iken, III. sınıf sular sulamaya uygun değildir (Prathap ve Chakraborty, 2020). Çalışma alanında her iki dönemde de yüzey sularının tamamının PI değerlerinin \%75'den daha düşük belirlenmiştir. Yine Haziran döneminde $6 \mathrm{su}$ örneğinde $(7,8,9,10,33$ ve 34 nolu örnekler) Eylül döneminde ise iki su örneğinde (10 ve 14) PI değerleri $\% 25$ 'in altında bulunmuştur. Her iki dönem bir arada değerlendirildiğinde, PI değerlerine göre, örneklerin \% 92 'sinin II. Sınıfa girdiği ve sulamaya uygun olduğu belirlenmiştir.

\section{$M R$}

Magnezyum tehlikesi (MR) değerleri \% 50'den büyük olan sular sulamaya uygun değildir (Prasanth ve ark. 2012). Çalışma alanından alınan yüzey suyu örnekleri bu kıstasa göre değerlendirildiğinde, bunların \% 70.6'sının sulamaya uygun olmadığı görülmektedir.

\section{Yüzey sularının içme amaçlı uygunluğu}

Çalışma alanındaki yüzey sularının içme suyu amaçlı uygunluğu Dünya Sağlık Örgütü'nün (WHO, 2004) kıstaslarına göre değerlendirilmiştir. Yüzey sularının $\mathrm{pH}$ değerleri 7.58 ile 9.75 arasında değişmiştir. Yüzey su örneklerinin yaklaşık \% 56'sı WHO tarafından belirlenen sınırlar (7.0-8.5) arasında kalmıştır.

Yüzey sularının tamamı, Dünya Sağlık Örgütü (WHO, 2004)'nün içme suları için istenilen EC $750 \mu \mathrm{S} \mathrm{cm}{ }^{-1}$ 'nin üzerinde çıkmıştır. Yine her iki dönemdeki toplam 99 yüzey suyu örneğinin 32 tanesinin EC'si aşılmaması gereken $1500 \mu \mathrm{S} \mathrm{cm}^{-1}$ değerinin altında bulunmuştur. Yüzey suyu örneklerinin tamamının toplam sertlik değerleri (TS), içme açısından herhangi bir risk

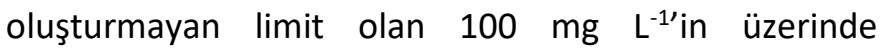
bulunmuştur.

Yüzey sularının \% 33.3'ü Na açısından herhangi bir risk oluşturmadan içilebilecek limit olan $50 \mathrm{mg} \mathrm{L}^{-1}$ nin altında bulunmuştur. Yine örneklerin \% 18.2'sinde $\mathrm{Na}$ konsantrasyonu, içme sularındaki $\mathrm{Na}$ için izin verilen maksimum sınırın (200 $\mathrm{mg} \mathrm{L}^{-1}$ ) üzerinde bulunmuştur. Örneklerin \% 70.7'sindeki Ca konsantrasyonları içme amaçlı kullanım için istenen $75 \mathrm{mg} \mathrm{L}^{-1}$ değerinin altında bulunmuştur. Buna karşın sadece \% 9.1'i maksimum izin verilen değerin (200 $\mathrm{mg} \mathrm{L}^{-1}$ ) üzerinde bulunmuştur. Örneklerin \% 72.7'sinde $\mathrm{Cl}$ konsantrasyonları, içme suları için olması istenen limitin $\left(250 \mathrm{mg} \mathrm{L}^{-1}\right)$ altında belirlenmiştir. Yüzey suyu örneklerinin \% 54.5'inde $\mathrm{SO}_{4}$ konsantrasyonu, içme suları için önerilen limitin (200 mg $\mathrm{L}^{-1}$ ) altında iken, \% 19.2' sinde aşılmaması gereken limitin (600 $\mathrm{mg} \mathrm{L}^{-1}$ ) üzerinde bulunmuştur.

Amik ovası Türkiye'nin en önemli ovalarından biridir. Ovada çok çeşitli bir ürün deseni bulunmaktadır. Ancak bu kadar önemli olan ovada yaz aylarında sulama suyu sıkıntısı yaşanmaktadır. Ova'nın en önemli su kaynağı olan Asi Nehri yaz aylarında kuruma noktasına gelmektedir. Diğer su kaynakları ise Afrin çayı ile Karasu çayı ve Comba kanalıdır. Drenaj kanallarının çoğu bu üç çay ve kanala bağlanmış durumdadır Bu nedenle Asi dışındaki yüzey su kaynaklarının kalitelerinin belirlenmesi sürdürülebilir tarım açısından son derece önemlidir. Çoğu yıllarda ovada yazın sulama amacı ile drenaj suları kullanılmaktadır.

Amik ovası gibi kurak ve yarı kurak bölgelerde, hem içme hem de sulama amaçlı yeterli suyun bulunması büyük önem arz etmektedir. Asi nehri Amik ovasında en önemli su kaynağıdır. Ancak sulama sezonunda nehrin Türkiye kısmındaki su miktarı çok azalmaktadır. Bu nedenle ovada yazın büyük bir su açığı ortaya çıkmaktadır. Çiftçiler kaynaklarından sağlamaya çalışmaktadır. Ancak bu suların önemli bir kısmının sulama ve içme amaçlı olarak uygun olmadığı görülmektedir. Bu nedenle bu suların özellikle sulamada kullanılması topraklarda tuzluluk ve alkalilik gibi önemli sorunlar ortaya çıkartabilmektedir. Bu nedenle ova için gerek içme gerek se sulama amaçlı daha temiz su kaynaklarının bulunması zorunluluk gibi görülmektedir. Ayrıca, ovada daha az su kullanımını sağlayan damla sulama yöntemi gibi yöntemlerin yaygınlaştırılması gerekir. Ayrıca, ova köylerinde yaşayan insanlar için de temiz içme suyu kaynaklarının bulunması gerekir.

Yüzey suyu örneklerinin EC ve SAR değerleri dikkate alındığında, örneklerin alındığı noktadaki suların büyük bir çoğunluğunun içme ve sulama amaçlı uygun olmadığı görülmektedir. Sular RSC yönünden kaliteli olup, bu kıstas açısından tamamı sulama ve içme amaçlı uygun olduğu görülmektedir. Diğer yandan toplam sertlik açısından bakıldığında suların tamamının içmeye uygun olmadığı görülmektedir. Gerek sulama gerekse içme amaçlı bakıldığında, incelenen kıstaslar bazında, yüzey su kaynakları arasında en temiz olanının Asi nehri olduğu belirlenmiştir. 


\section{ÖZET}

Amaç: Bu çalışmada, Amik Ovası'ndaki yüzey sularının özelliklerinin belirlenmesi ve bunların içme ve sulama suyu kalitesi amaçlı değerlendirilmesi amaçlanmıştır.

Yöntemler ve Bulgular: Çalışmada, Amik Ovasındaki yüzey su kaynaklarından Haziran ve Eylül 2017'de 56 noktadan, toplam 99 su örneği alınmıştır. Örneklerde, $\mathrm{pH}$, elektriksel iletkenlik (EC), toplam çözünebilir katılar (TDS), katyon ve anyon analizleri yapılmıştır. Ayrıca anyon ve katyonlardan sodyum adsorpsiyon oranı (SAR), magnezyum oranı (MR), geçirgenlik indeksi (PI), toplam sertlik (TS) ve kalıcı bikarbonat (RSC) değerleri hesaplanmıştır. Analiz sonuçlarına göre, Haziran ayında dominant katyon $\mathrm{Mg}$ iken en düşük konsantrasyona sahip katyon ise K; konsantrasyonu en yüksek olan anyon $\mathrm{SO}_{4}$, en düşük olanın $\mathrm{CO}_{3}+\mathrm{HCO}_{3}$ olduğu belirlenmiştir. Eylül ayında da en yüksek ve en düşük katyon konsantrasyonları Haziran ayındaki gibi olmasına rağmen, bu aydaki konsantrasyonu en yüksek olan anyon $\mathrm{Cl}$ olmuştur. Amerikan tuzluluk laboratuvarı diyagramına göre, suların her iki dönemdeki kalite sınıfları C3S1 ile C4S3 arasında değişmiştir.

Genel Yorum: tanımlayıcı istatistiksel analiz sonuçlarından elde edilen standart sapma ve ortalama değerlerden hesaplanan varyasyon katsayılarına göre; her iki dönemde de en düşük varyasyon katsayısı pH değerlerinde saptanmıştır. Haziran dönemindeki ortalama $\mathrm{pH}$ değeri, Eylül dönemi $\mathrm{pH}$ değerlerinden istatistiksel olarak anlamlı bir şekilde yüksek bulunmuştur $(p<0.05)$. Diğer yandan, Eylül dönemindeki ortalama SAR değeri, Haziran dönemindeki SAR değerinden istatistiksel olarak \%1 düzeyinde önemli bulunmuştur. Çalışma alanında her iki dönemde de yüzey sularının tamamının geçirgenlik indeksi (PI) değerlerinin $\% 75$ 'den daha düşük olduğu belirlenmiştir.

Çalışmanın Önemi ve Etkisi: Yüzey suyu örneklerinin EC ve SAR değerleri dikkate alındığında, örneklerin alındığı noktadaki suların büyük bir çoğunluğunun içme ve sulama amaçıı uygun olmadığı görülmektedir. Diğer yandan toplam sertlik açısından bakıldığında suların tamamının içmeye uygun olmadığı görülmektedir.

Anahtar kelimeler: Amik ovası, geçirgenlik indeksi, su kalitesi, yüzey suları.

\section{TEŞEKKÜR}

Bu çalışma Hatay Mustafa Kemal Üniversitesi Bilimsel Araştırma Projeleri Koordinatörlüğü tarafından desteklenen projeden (Proje No: 15582) üretilmiştir.

\section{ÇIKAR ÇATIŞMASI BEYANI}

Makale yazarları aralarında herhangi bir çıkar çatışması olmadığını beyan ederler.

\section{ARAŞTIRMACILARIN KATKI ORANI BEYANI}

Araştırmaya her iki yazar da eşit oranda katkı sağlamıştır.

\section{KAYNAKLAR}

Ağca N (2014) Spatial variability of groundwater quality and its suitability for drinking and irrigation in the Amik Plain (South Turkey). Environ. Earth Sci. 72: 4115-4130.

Ağca N, Karanlık S, Ödemiş B (2014) Assessment of ammonium, nitrate, phosphate, and heavy metal pollution in groundwater from Amik Plain, southern Turkey. Environ. Monit. Assess. 186: 5921-5934.

Ağca N, Doğan K, Akgöl A (2000) Amik ovasında yer alan bazı topraklarda tuzluluk ve alkaliliğin boyutları üzerine bir araştma. MKÜ. Ziraat Fakültesi Dergisi 5(12): 29-40.

Ahsan WA, Ahmad HR, Farooqi ZUR, Sabir M, Ayub MA, Rizwan M, llic P (2021) Surface water quality assessment of Skardu springs using water quality Iindex. Environmental Science and Pollution Research 28: 20537-20548.

Ayers RS, Westcot D W (1994) Water quality for agriculture. FAO irrigation and drainage paper No. 29, Rev. 1.

Arumugam K, Elangovan K (2009) Hydrochemical characteristics and groundwater quality assessment in Tirupur Region, Coimbatore District, Tamil Nadu, India. Environ. Geol. 8: 1509-1520.

Bilgin A (2015) An assessment of water quality in the Coruh Basin (Turkey) using multivariate statistical techniques. Environ. Monit. Assess. (2015) 187: 721.

Eaton FM (1950) Significance of carbonates in irrigation waters. Soil Sci. 39: 123-133.

Goovaerts P (1999) Geoistatistics in soil science: Stateof-the art and perspectives. Geoderma 89: 1-45.

Gün M, Erdem AM (2003) Hatay master planı. Tarım ve Köyişleri Bakanlığı, Hatay Tarım il Müdürlüğü.

Keskin F, Aydın M, Ağca N (1999) Amik ovasında tuzdan etkilenmiş topraklardan bir kesit. MKÜ. Ziraat Fakültesi Dergisi 4(1-2): 55-70.

Khadka RB, Khanal AB (2008) Environmental management plan (EMP) for Melamchi water supply project, Nepal. Environmental Monitoring and Assessment 146(1-3): 225-234. 
Kılıç Ş, Ağca N, Karanlık S, Şenol S, Aydın M, Yalçın M, Çelik I, Evrendilek F, Uygur V, Doğan K, Aslan S, Çullu MA (2008) Amik ovasının detaylı toprak etütleri, verimlilik çalışması ve arazi kullanım planlaması. MKÜ. Ziraat Fakültesi Toprak Bölümü, Bilimsel Araştırma Projeleri Komisyonu Proje No: DPT2002K120480. $213 \mathrm{~S}$.

Kirda C (1997) Assessment of irrigation water quality. Options Méditerranéennes, Séminaires Méditerranéens pp. 367-377.

Lorrane de Oliveira K, Ramos RL, Oliveira SC, Christofaro C (2021) Spatial variability of surface water quality in a large Brazilian semiarid reservoir and its main tributaries. Environ. Monit. Assess. 187: 548.

Muangthong S, Shrestha S (2021) Assessment of surface water quality using multivariate statistical techniques: case study of the Nampong River and Songkhram River, Thailand. Environ. Monit. Assess. 193: 409.

Monaj K, Kumar B, Padhy PK (2013) Spatial assessment and characterisation of the Subarnarekha river water through index analyses approaches and chemometrics. The Eroscan (special issue) 3: 321330.

Prasanth SVS, Magesh NS, Jitheshlal KV, Chandrasekar N, Gangadhar K (2012) Evaluation of groundwater quality and its suitability for drinking and agricultural use in the coastal stretch of Alappuzha District, Kerala, India. Appl. Water Sci. 2: 165-175.

Prathap A, Chakraborty S (2020) Assessment of surface water quality around opencast coal mines for sustainable utilization potentials: a case study in Jharkhand, India. Environment, Development and Sustainability 22: 3179-3205.

Richards LA (1954). Diagnosis and improvement of saline and alkali soils. US Dep Agri. Handbook. 60: 147.

Rim-Rukeh A, Ikhifa GO, Okokoyo PA (2007) Physicochemical characteristics of some waters used for drinking and domestic purposes in the Niger Delta, Nigeria. Environ. Monit. Assess. 128: 475-482.

Ruždjak AM, Ruždjak D (2015) Evaluation of river water quality variations using multivariate statistical techniques. Sava River (Croatia): a case study. Envir. Monit. Assess. 187: 215.

Samarghandi MR, Nouri J, Mesdaghinia AR, Mahvi AH, Nasseri S, Vaezi F (2007) Efficiency removal of phenol, lead and cadmium by means of UV/TiO2/H2O2 processes. International Journal of Environmental Science \& Technology 4(1): 19-25.
Smith VH (2003) Eutrophication of freshwater and coastal marine ecosystems a global problem. Environmental Science and Pollution Research 10(2): 126-139.

Taher ME, Ghoneium AM, Hopcroft RR, ElTohamy WS (2021) Temporal and spatial variations of surface water quality in the Nile River of Damietta Region, Egypt. Environ. Monit. Assess. 193: 128.

Ustaoğlu F, Tepe Y, Taş B (2019) Assessment of stream quality and health risk in a subtropical Turkey river system: A combined approach using statistical analysis and water quality index. Ecological Indicators, https://doi.org/10.1016/j.ecolind.2019.10815.

Ustaoğlu F, Taş B, Tepe Y, Topaldemir H (2021). Comprehensive assessment of water quality and associated health risk by using physicochemical quality indices and multivariate analysis in Terme River, Turkey. Environmental Science and Pollution Research 1-19.

Wang MH, Duan LJ, Wang JP, Peng JY, Zheng BH (2020) Determining the width of lake riparian bufer zones for improving water quality base on adjustment of land use structure. Ecol. Eng. 158: 106001.

WHO (2004) Guidelines for drinking water quality. Vol.1. Recommendation. World Health Organization, Geneva, ISBN 9241546387.

Yadav SS, Kumar R (2011) Monitoring water quality of Kosi river in Rampur district, Uttar Pradesh, India. Advances in Applied Science Research 2(2): 197-201.

Zeeshan M, Azeez PA (2016) Hydro-chemical characterization and quality assessment of a Western Himalayan river, Munawar Tawi, flowing through Rajouri district, Jammu and Kashmir, India. Environ. Monit. Asses. 188: 520.

Zhou Z, Zhang G, Wang J (2011) Spatial variability of the shallow groundwater level and its chemistry characteristics in the low plain around the Bohai Sea, North China. Environ. Monit. Assess. doi. 10.1007/s10661-011-2217-1. 